\title{
IMPROVING CLIENT SERVICE RELIABILITY IN COLLABORATIVE SUPPLY CHAINS: A MAS SCHEDULER
}

\author{
Pedro Gómez, Raúl Rodriguez, Rubén Darío Franco and Angel Ortiz \\ Research Centre on Production Management and Engineering \\ Polytechnic University of Valencia \\ Camíno de Vera $S / N$. Edificio $8 G$, Acceso D Planta $1^{\circ}$ \\ Tel. (+34) 96.387.96.80/Fax: (+34) 96.387.76.89 \\ \{pgomez |raulr_dfranco|aortiz\}@cigip.upv.es
}

\begin{abstract}
The theory of network coordination provides a theoretical basis to explain how companies can overcome organizational boundaries and constraints to jointly manage business processes across supply chains. In particular, this paper focuses on Collaborative Scheduling, a collaboration process whereby Supply Chain trading partners activate on-line inter-firm coordination mechanisms to jointly plan key activities, from production and delivery of raw materials to production and delivery of final products to end customers.

By discussing a case study of ceramic tile the paper provides a theoretical framework that contributes to explaining the relations between inter-firm coordination mechanisms and the characteristics of interdependence among the actors involved in the implementation. To automate the coordination process a generalized agent-based framework that uses negotiation to dynamically schedule events is presented. Events can be created dynamically and event may potentially require collaboration or resources from one or more other actors/agents. The allocation of resources to the event will be negotiated iteratively until a compromise is found. The framework consists of a user preference model, an evaluation or utility function, and a negotiation protocol.
\end{abstract}

\section{INTRODUCTION}

This paper presents an introduction to the problematic of order management within extended collaborative selling chains (ECOSELL), and an identification of the objectives and requirements of this environment. Then, the main operations to be considered at the ECOSELL context are order planning, scheduling and monitoring, whose final goal is to meet the delivery date agreed with final customers.

Therefore, a proposal about the different roles of the actors and main processes detected within this ECOSELL environment is presented. Finally, a Multi-Agent System (MAS) architecture is introduced for dealing with the described problem. 


\section{SUPPLY CHAIN COLLABORATION}

Nowadays, globalisation and enhanced national, European and worldwide competitiveness have promoted the creation and consolidation of the so-called EE, which transcend the single enterprise domain and build meta-enterprises [3].

Most existing EE have initially focused on reinforcing the links and flows between companies that are involved in the same value chain [6]. However, recently, the phenomenon has shifted toward the creation of EE that cross the barriers of a single value chain, and link different complementary value chains building collaborative selling chains. Many industrial companies have wanted to or have been selling and distributing jointly their aggregated products for a long time and now face the challenge of the complete integration of their value chains. [2].

This move from the meta-enterprise to the meta-value chain can be easily explained. In a world where the customer has become the new king, companies have to be fully customer-oriented, -customised and -governed in order to maintain their competitive advantage [4]. The starting point of any meta-value chain winning approach is consequently collaboration, where the concepts inherently implies agility and learn to learn capacity [7]

The selling chain focuses on the management of orders life cycle, from the initial order placement to the delivery and provision of physical goods, covering the part of the value chain that goes from manufacturers to end customers (including logistics platforms/operators, distribution, intermediaries, resellers and retailers). The order promising process comprises the set of activities that are triggered in order to give a response to the customer order requirements.

\section{COLLABORATIVE PROCESSES IN THE ECOSELL FRAMEWORK}

The business processes considered in this study include order planning, scheduling, and monitoring. The goal of these processes is the fulfilment of requested orders on agreed time (see Figure 1).

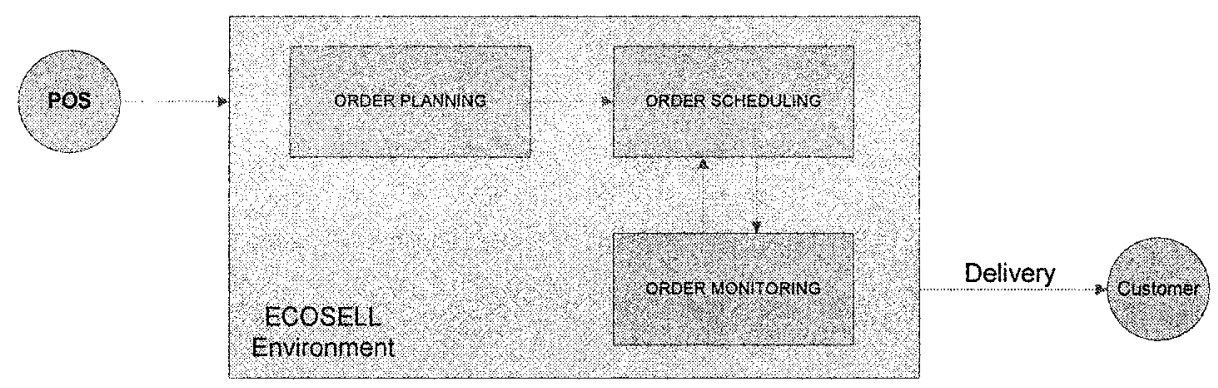

Figure 1 - ECOSELL environment

The Ecosell Environment must deal with a set of interrelated business processes, which are briefly described next: 
1) Order planning: Customers look for packaged products in one Point of Sales (PoS). This process takes into account availability, capacity, constrains and stock already available in some store, in order to prepare the "installation program".

2) Order Scheduling: With such a calendar on hand, the system must check the requirements of the customer order at every distribution point (places with physical availability of products or available capacity for manufacturing it), always taking into account the specific conditions of the order (dates, capacity or costs).

3) Order Monitoring: The order's life cycle ends when the products that constitute the product pack are delivered to the customer. In the middle, several events may affect the original schedule (delays, temporary incapacity, quality problems). If one of these circumstances affects the "critical path" of the order, the system must initialize a re-scheduling process in order to allocate new dates on available capacities.

Then, the scenario of the problem can be depicted as follows (see Figure 2):

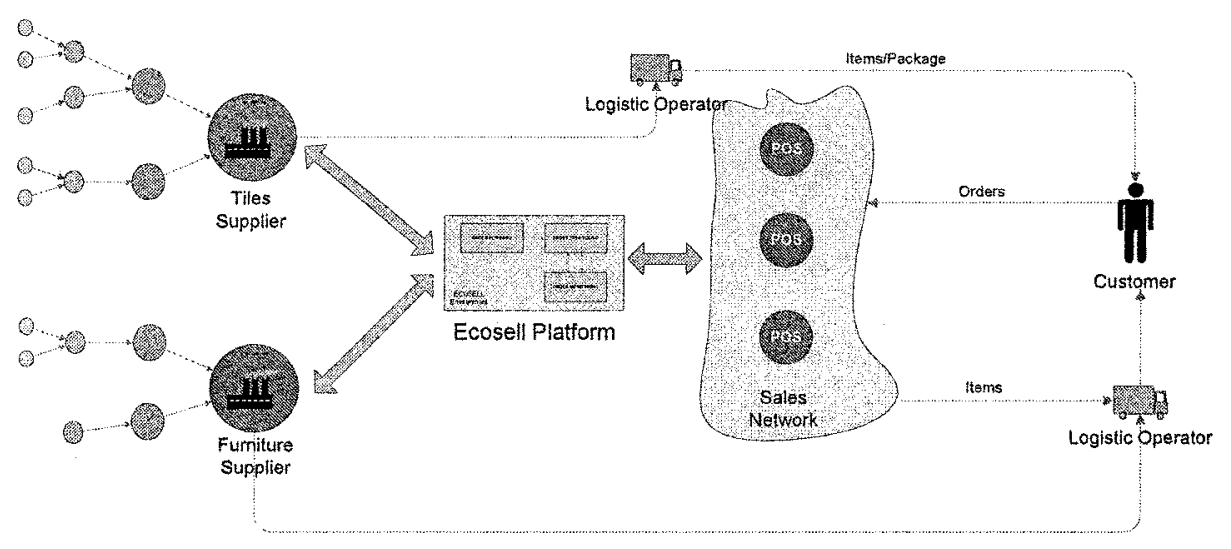

Figure 2 - Actors involved in the Ecosell Environment

This scenario presents a set of characteristics that highly increase the degree of complexity when proceeding to model it as:

- Companies must work cooperatively to properly coordinate decentralized scheduling activities for all SC involved because all of them may have heterogeneous scheduling systems

- The uncertainty about the actual "situation" in individual plants has to be regarded.

- Interdependencies between production processes that are performed in different plants have to be regarded.

- Existing (local) scheduling systems for individual plants that accomplish the local realisation of global requirements should be integrated. 


\section{MULTI AGENT SYSTEMS AS SUPPORT OF EXTENDED COLLABORATION}

Conducting business transactions over the Internet is a well-known issue today (for projects and research trends see [10]), which has been addressed in vast research works. One of the most promising enabling technologies are those represented by the combination of human and system tasks in solving complex tasks [8].

All these features of the problem can be well addressed by an agent-supported ICT infrastructure. In fact, huge research work has been done in this sense, applying these concepts to several domains [1], [5]]. The main characteristics are:

- Decentralised and local task processing: Agents enable the automated distribution of formerly centralised programmes.

- Flexibility: On-demand software distribution / service provisioning service.

- Automation of distributed task processing: Agents have got itineraries that determine what tasks they have to perform where without any user interaction.

- Reduction of network traffic and client processing power: Since massive data exchanges are locally handled at the nodes hosting, the data and client computers could concentrate on performing only limited local tasks,

Next section introduces an innovative approach by applying Multi-Agent System principles when product-packs are sold through a Sales Network and effective and efficient mechanisms of negotiation and co-ordination for assuring proper order fulfilment are demanded.

\section{CASE STUDY}

This case study focuses on the order management process of the bathroom product. The goal is to sell product-packs, which can be constituted by ceramic tiles, furniture, bathroom fittings and lamps.

\subsection{Conceptual Description}

The process starts when a final customer walks into a selling point and identifies a conjoint of products that might constitute a product-pack for his bathroom. Such items must be delivered and installed at the customer's house by accomplishing a calendar, which must respect the following constraints:

(1) The range of delivery dates facilitated by the customer.

(2) The dependencies between the operations of installation of every product. There is a graph of dependencies that determines both the sequence and the relationships among the items.

(3) To minimise the time frame between the starting operation and the final installation at the customer's house.

The order management system must find a proper solution for every particular case according to the above stated constraints. It must also solve unexpected events by 
carrying out re-scheduling operations that respect the promised delivery date or, if it is not possible, to come up with a close one in time.

It is established as objectives for each offer to maximise B (Equation 1) and to minimise nweeks, where $\mathrm{B}$ is the sum of $\mathrm{Bi}$ (Equation 2), the obtained final benefit from each product, and nweeks is the number of weeks between the best delivery date (proposed by the customer) and the delivery of the pack-product. Equation 3 illustrates the proposed objective function.

(Eq. 1) $B=\sum_{i} B_{i}$

(Eq. 2) $B_{i}=\left(S P-\sum C\right)$, where PS is the fixed selling price (official) and $C$ the total cost (from suppliers and carriers).

$$
\text { (Eq. 3) } f=\frac{\sum_{i} B_{i}}{n \text { weeks }}
$$

Table I shows an example of how the different values from the objective function change according to the benefits gained by each item and the worst delivery date that comes from the item with the worst time of response. The first row shows the results of the first petition (petition without re-scheduling).

\section{Scheduling conditions:}

Minimum Benefits: 500 Euros

Number of weeks from now: 10 weeks

\begin{tabular}{|c|c|c|c|c|c|}
\hline & $\begin{array}{l}\text { Function } \\
\text { Vatue }\end{array}$ & $\begin{array}{l}\text { Ceramic } \\
\text { Tlle }\end{array}$ & $\begin{array}{l}\text { Bathroom } \\
\text { Fittings }\end{array}$ & Furniture & Lamps \\
\hline Initial Offers & $\begin{array}{l}\text { Beneft: } 1200 \\
\text { D. date; } 6 \mathrm{w} \\
F=200\end{array}$ & $\begin{array}{l}\text { Benefit: } 3506 \\
\text { D. Date: } 6 \mathrm{~W} .\end{array}$ & $\begin{array}{l}\text { Benefit: } 2006 \\
\text { D. Date: } 3 \text { w. }\end{array}$ & $\begin{array}{l}\text { Beneft: } 500 € \\
\text { D. Date: } 6 \text { w. }\end{array}$ & $\begin{array}{l}\text { Benefit: } 1506 \\
\text { D. Date: } 2 w .\end{array}$ \\
\hline $\begin{array}{l}\text { Negotiation } \\
\text { process on } \\
2 \text { steps }\end{array}$ & $\begin{array}{l}\text { Benent: } 650 \\
\text { D. date: } 3 w \\
F=216,7\end{array}$ & & $\begin{array}{l}\text { Eenefit: } 2006 \\
\text { D. Date: } 3 w \text {. }\end{array}$ &  & $\begin{array}{l}\text { Benefit: } 150 € \\
\text { O. Oate: } 2 w .\end{array}$ \\
\hline & $\begin{array}{l}\text { Beneft: } 850 \\
\text { D. date: } 3 \mathrm{w} \\
F=283,3\end{array}$ & Gereet 2000 & $\begin{array}{l}\text { Beneft: } 2004 \\
\text { D. Oate: } 3 \mathrm{w} .\end{array}$ & $\begin{array}{l}\text { Beneft: } 300 \mathrm{e} \\
\text { D. Date: } 3 \mathrm{w}\end{array}$ & $\begin{array}{l}\text { Benest: } 1508 \\
\text { D. Date: } 2 \mathrm{w} .\end{array}$ \\
\hline $\begin{array}{l}\text { Negotiation } \\
\text { process } \\
\text { aborted }\end{array}$ & $\begin{array}{l}\text { Benefit: } 250 \\
\text { D. date: } 2 w \\
F=125\end{array}$ & & & 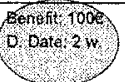 & $\begin{array}{l}\text { Benefft: } 1506 \\
\text { D. Date: } 2 \mathrm{w} .\end{array}$ \\
\hline
\end{tabular}

Table I. An example of the evolution of the objective function, in a process of negotiation.

The rows 2 and 3 show the first negotiation process in a two-steps process. The step 1 selects the item (furniture), it has the worst delivery time but provides the highest time of response, asking then for an offer with re-scheduling. The representative item answers with a delivery date of 3 weeks, reducing the benefit to $300 €$. As it is observed that this offer supposes an increment over the objective function (still without checking the ceramic tile's contribution), it is not rejected, establishing the second step for the offer negotiation with the ceramic tile representative. In the last row, it is aimed to carry on with the improvement of the 
objective function, starting to negotiate with the item that more benefit provides after the last round. The negotiation process is cancelled since it cannot either overpass the last value of the objective function nor to reach the minimum objective of $500 €$. Therefore, the two last negotiated offers are accepted: furniture $(-300 €, 3$ weeks), ceramic tile (-200€, 3 weeks).

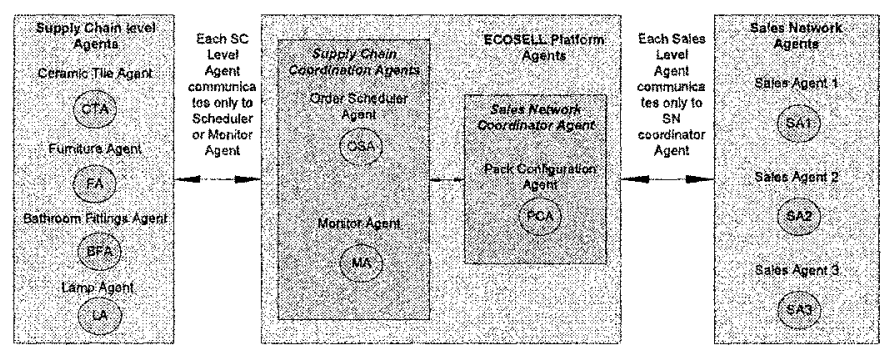

Figure 3 - Multiagent System Architecture

\subsection{Mapping the organization and Roles to Multi-agents Architecture}

In this case study, an ECOSELL environment is represented by a multi-agent system. In our case, each actor is represented by an agent. The agents created can be seen in figure 3.

\section{Pack Configuration Agent}

The Pack Configuration agent is the responsible for coordinating the order with the user interface agent (generator of an enquiry offer) and with the rest of agents. The Pack Configuration agent asks for the rest of selling points for asking about inventory levels from others warehouses; and also with the order scheduler agent for asking for the production of some item.

\section{Order Scheduling Agent}

The Order scheduler agent asks offer from the supply chain level agents for completing the offer already sent by the pack configuration agent. Then, it initiates a process of improving the received offers until to reach an adequate offer regarding the value of the objective function to be maximised.

\section{Monitoring Agent}

Finally, the Monitoring Agent is responsible of receiving from the supply chain level agent those events that could have relation with the different compromised orders.

\subsection{Order Scheduler Agent-Supply Chain Level Agents Relationship}

The Scheduler will ask from the supply chain agent offers enquiries for assessing them in its programme algorithm and then either to accept or to reject them. Two main difficulty levels within the SC level agents are distinguished when answering an order enquiry: 
- When the supply chain agent does not carry out any sort of re-scheduling operations between its programs.

- When the supply chain agent allows assessing options that suppose rescheduling. In this case, a change is forced, which can or cannot have consequences for other customer and which can suppose a higher cost in the offer.

\subsection{Order Scheduler Agent - Supply Chain Level Agent: Negotiation Process}

Finally the activity diagram showed in Fig. 4 represents the scheduler agent negotiating with all the $\mathrm{SC}$ level agents. The key actions stated in our algorithm are the steps enumerated in Figure 4.



Figure 4. UML Activity Diagram of the Negotiation Algorithm.

\section{CONCLUSIONS}

Customers are acquiring more buying power as they access to more reliable and complete information about products. Nowadays, buying experiences requires mores skills form sales people. Points of sales are demanding more efficient tools to properly react to always evolving customer's needs. 
This paper has presented an introduction to the problematic of order management within extended collaborative selling chains (ECOSELL), where an identification of the objectives and requirements necessary of this environment. Then, the main operations at the ECOSELL context (order planning, scheduling and monitoring) that need to be addresses were introduced. Therefore, a proposal about the different roles of the actors and main process detected within this ECOSELL environment was identified.

A Multi-Agent System (MAS) architecture was introduced for dealing with the described problems, focusing on the scheduler function and on the negotiation processes of such MAS with the different actors form the different supply chains in order to reach competitive offers.

\section{Acknowledgements}

This paper is based on researching developed within the EU-founded ECOSELL project (GRD1-2001-40692).

\section{REFERENCES}

1. Baker, A., Van Dyke Parunak, H. and Kutluhan Erol(1999)."Agents and The Internet: Infrastructure for Mass Customization". IEEE Internet Computing, Vol 3, No 5

2. Burton, T.T. and Boeder, S.M (2003): The Lean Extended Enterprise: Moving Beyond the Four Walls to Value Stream Excellence. J. Ross Publishing, Inc. Florida.

3. Dyer, J. H. (2000), Collaborative Advantage: Winning Through Extended Enterprise Supplier Networks. Oxford University Press. New York.

4. Goranson, H.T. (1999)," The Agile Virtual Enterprise. Cases, Metrics, Tools", Quorum Books.

5. Kim, K., Paulson, B. Jr., and Petrie, Ch. Jr, (1999). "Agent-Based Electronic Markets for Project Supply Chain Coordination". Papers from the AAAI Workshop. Technical Report WS-00-04.

6. Macbeth, (1998), Partnering Strategy Implementation in the Supply Chain, Strategic Management of the Manufacturing Value Chain, Bittici U., Carrie A. (Edits.) Kluwer

7. Meier, J. (1995), The importance of relationship management in establishing successful interorganizational systems, Journal of Strategic Information Systems, Volume 4, Issue 2, pp. $135-148$

8. Papazoglou, M. (2001). "Agent-oriented technology in support of e-business". Communications of the ACM. Vol $44, \mathrm{~N}^{\circ} 4$

9. Papazoglou, M.P., Laufmann, S. and Sellis, T.K. (1992) An organizational framework for cooperating intelligent information systems. International Journal of Cooperative Information Systems 1,1.

10. Virtual Organizations Forum (2004). Research projects and issues. Reachable at www.virtualorganization.net. 